\title{
Strength of 3Y-TZP and feldspathic porcelain subjected to different cooling methods
}

\author{
Antonio Alves de Almeida-Júnior ${ }^{1}$, Diogo Longhini², Beatriz Regalado Galvão³, \\ Claudinei dos Santos ${ }^{4}$, Gelson Luis Adabo ${ }^{2}$
}

\author{
${ }^{1}$ Universidade Tiradentes - UNIT, School of Dentistry, Department of Oral Rehabilitation, Aracaju, SE, Brazil \\ 2Universidade Estadual Paulista - UNESP, School of Dentistry, Department of Dental Materials and Prosthodontics, Araraquara, SP, Brazil \\ ${ }^{3}$ Universidade Potiguar - UnP, School of Dentistry, Department of Oral Rehabilitation, Natal, RN, Brazil \\ ${ }^{4}$ Universidade do Estado do Rio de Janeiro - UERJ, Resende School of Technology, Department of Engineering Materials, Resende, RJ, Brazil
}

\begin{abstract}
Aim: To investigate the effect of the cooling rate on flexural strength of monolayer and bilayer porcelain/zirconia (Y-TZP) bars. Methods: Forty-five specimens were made for each design group: (PM) monolithic specimens of veneer porcelain Vita VM9 (Vita, Germany); (ZM) monolithic specimens of zirconia (ZiHP; ProtMat, Brazil); (PB) bilayer specimens zirconia/porcelain with porcelain on lower surface; and (ZB) bilayer specimens porcelain/zirconia with zirconia on lower surface. Each group was cooled by three different methods after porcelain sintering: slow specimens were cooled inside the turned-off furnace; normal - specimens were removed from the furnace and cooled in air at room temperature; and fast - specimens were removed from the furnace at $910^{\circ} \mathrm{C}$ and cooled by compressed air for $10 \mathrm{~s}$. Specimens were polished and flexural strength was measured in water at $37^{\circ} \mathrm{C}(\mathrm{n}=15)$. Maximum load at fracture was recorded, and equations for simple (monolayer) and composite (bilayer) structures were used to calculate the flexural strength. Results were analyzed using one-way ANOVA $(p<0.05)$ and Tukey test separately for each design. Results: The results of one-way ANOVA were statistically significant only for the PB group. The post-hoc Tukey test showed the highest flexural strength for fast cooling and the lowest for slow cooling; the normal cooling was statistically similar to both. Conclusions: Cooling methods affected only the flexural strength of bilayer specimens with porcelain on low surface (under tension) when the slow cooling method was used.
\end{abstract}

Keywords: dental porcelain; zirconium; material resistance.

\section{Introduction}

Medical applications of ceramic system based on Yttria-stabilized zirconia (3Y-TZP) have increased due to its biological and mechanical properties and improvement in computer-aided design/computer-aided manufacturing (CAD/

Received for publication: April 06, 2014 Accepted: June 09, 2014

Correspondence to: Gelson Luis Adabo Rua Humaitá, 1680. Sala 415. Centro CEP 14801-903 Araraquara, SP, Brasil Phone: +55 16 3301-6415 Fax: +55 16 3301-6406 E-mail: adabo@foar.unesp.br CAM) technology. Zirconia was introduced into the dental market as framework for ceramic fixed partial dentures due to its sufficient strength and toughness, and it is believed to resist the masticatory forces in posterior teeth, comparable to several metal-ceramic alloys ${ }^{1}$. However, high crystalline zirconia is an opaque material, and, for esthetical reasons, 3Y-TZP frameworks have to be veneered with specific feldspathic dental porcelains ${ }^{2}$.

Nevertheless, the veneer porcelain is the weakest part of this system due to its low content of crystalline phase. Moreover, this system seems to behave 
differently from conventional metal-ceramic prostheses. After three years of service time, chipping of zirconia porcelains is described to have a failure rate of $15 \%$, while this rate for metal-ceramic prostheses is less than $0.5 \%$ for crowns and $3 \%$ for fixed partial denture in five years ${ }^{3-6}$.

Among the reasons for failure, residual tension is the most discussed issue in the literature ${ }^{7-11}$. Incompatible thermal expansion coefficient ${ }^{7}$, non-uniform porcelain thickness ${ }^{12}$, inadequate substructure design ${ }^{13}$, low thermal conductivity of zirconia, fast cooling rates ${ }^{11}$, and intrinsic strength of these ceramic materials ${ }^{14-15}$ may develop tension stress in the system and induce the occurrence of failures in $3 \mathrm{Y}-\mathrm{TZP} /$ porcelain prostheses ${ }^{10,15}$. Moreover, zirconia and metal frameworks behave differently after porcelain sintering. During the cooling, an excessive compressive stress may be compensated by plastic flow or thermal creep of the metal, while similar compensation is not possible in 3Y-TZP frameworks because of its high rigidity. Therefore, veneering materials for allceramic system should have high mechanical strength ${ }^{16}$.

Different cooling rates after porcelain firing schedule have been proposed for reducing those residual stresses ${ }^{10,17-18}$. The study of flexural strength of veneering porcelains and zirconia using faster or slower cooling is an important parameter to improve the clinical behavior and performance of veneered zirconia prostheses. The aim of this study was to investigate if cooling methods change the flexural strength on monolayer and bilayer specimens of zirconia and feldspathic porcelain subjected to different cooling methods. The null hypothesis was that the cooling method did not modify the flexural strength of monolayer and bilayer zirconia/porcelain specimens.

\section{Material and methods}

A three-point flexural strength test was performed in four different designs (Figure 1) of monolayer or bilayer bar specimens of 3Y-TZP (ZiHP; ProtMat Materiais Avançados, São Paulo, SP, Brazil) and feldspathic porcelain (VITA VM9; VitaZahnfabrik, Bad Säckingen, Germany) subjected to three different cooling methods.

Forty-five specimens of each design were prepared according to the dimensions recommended by ISO 6872:2008 for a three-point flexural strength test $(4 \pm 0.25 \mathrm{~mm}$ in width, $1.2 \pm 0.2 \mathrm{~mm}$ in thickness and $22 \mathrm{~mm}$ in length). The thickness of bilayer specimens was in a ratio of 1:1. Zirconia specimens were cut approximately $25 \%$ larger than the final dimensions with a diamond disk (15LC; Buehler Ltd, Lake Bluff, IL, USA) in a precision saw (ISOMET 2000; Buehler Ltd.) at low speed. After cutting, the specimens were ground using 600-grit silicon carbide $(\mathrm{SiC})$ abrasive papers (Norton Abrasivos, São Paulo, SP, Brazil) on a mechanical polisher (Buehler Metaserv 2000; Buehler UK Ltd., Coventry, England) under running water. The specimens were sintered in a $\mathrm{MoSi}_{2}$ oven (INTI FE 1800; Maitec, São Carlos, SP, Brazil) at $1.530^{\circ} \mathrm{C}$ for $2 \mathrm{~h}$, heating rate of $8{ }^{\circ} \mathrm{C} / \mathrm{min}$, and cooling rate of $5{ }^{\circ} \mathrm{C} / \mathrm{min}$, according to the manufacturer's recommendation. The firing schedules for zirconia and porcelain are shown in Table1.

Porcelain specimens were made by mixing VM9 powder and VITA Modeling Liquid (VitaZahnfabrik). Slurry was prepared and condensed into polyether mold (Impregum F; 3 M ESPE, Seefeld, Germany) 20\% larger than the final dimensions, to compensate for porcelain contraction. After the excess liquid had been soaked up with an absorbent tissue, the specimens were fired in an oven for ceramics (Aluminipress; EDG, São Carlos, SP, Brazil) according to the recommendations of the porcelain manufacturer (Table 1).

Table 1. Firing schedules of the materials

\begin{tabular}{lccc}
\hline Step & Zirconia & $\begin{array}{c}\text { Base Dentine } \\
\text { Washbake VM9 }\end{array}$ & $\begin{array}{c}\text { Base } \\
\text { Dentine VM9 }\end{array}$ \\
Pre-Drying Time $(\mathrm{min})$ & - & 2 & 6 \\
Pre-Drying Temperature $\left({ }^{\circ} \mathrm{C}\right)$ & - & 500 & 500 \\
Heating Rate $\left({ }^{\circ} \mathrm{C} / \mathrm{min}.\right)$ & 8 & 55 & 55 \\
Firing Temperature $\left({ }^{\circ} \mathrm{C}\right)$ & 1530 & 950 & 910 \\
Holding Time $(\mathrm{min})$ & 120 & 1 & 1 \\
\hline
\end{tabular}

For bilayer specimens, the porcelain manufacturer recommends the base dentine washbake firing previous to dentine porcelain. Washbake porcelain was applied on one side of the zirconia bilayer samples and fired according to the manufacturer's instructions (Table 1). After the washbake layer cooling, dentine porcelain was applied as previously described.

After porcelain firing (groups $\mathrm{PM}, \mathrm{PB}$, and ZB) or porcelain firing simulation for the $\mathrm{ZM}$ group, three cooling methods were performed $(n=15)$ : slow - samples were left inside the closed turned-off furnace until it reached the room temperature; normal - the elevator of the furnace was down,

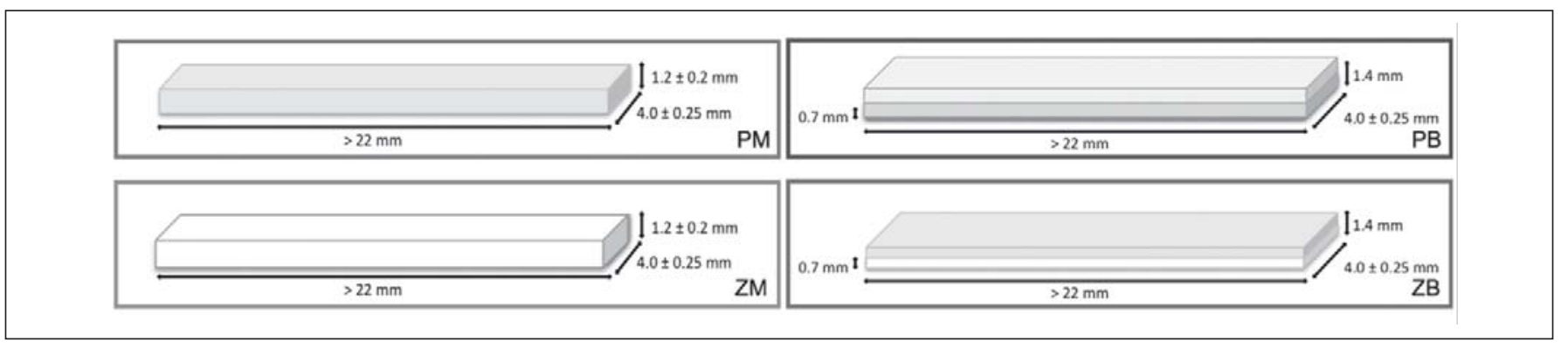

Fig. 1.Design groups: (PM) monolithic specimens of porcelain; (PB) bilayer specimens 3YTZP/VM9 with porcelain in lower surface; (ZM) monolithic specimens of 3YTZP; (ZB) bilayer specimens VM9/3Y-TZP with zirconia in lower surface 
and when the temperature inside the furnace reached $500^{\circ} \mathrm{C}$, the samples were removed and cooled in air at room temperature; fast - samples were blasted directly by compressed air immediately after removal from the furnace. When cooling was finished, the porcelain in the specimens were grounded and polished using 120-, 220-, 320-, 400-, 600-, and 1200-grit SiC abrasive papers (Norton Abrasivos Brasil, São Paulo, SP, Brazil) on a mechanical polisher (Buehler Metaserv 2000; Buehler UK Ltd.) under running water. Bilayer specimens were randomly allocated to the design group.

The three-point flexural strength test was performed in a universal testing machine (DL 2000; EMIC, São José dos Pinhais, PR, Brazil) with a $5.0 \mathrm{kN}$ load cell and at crosshead speed of $1.0 \mathrm{~mm} / \mathrm{min}$ until failure. The specimens were placed in the sample holder, which had a span of $15 \mathrm{~mm}$ between the two $0.8 \mathrm{~mm}$ radius rounded bearers and loaded by a 1.6 $\mathrm{mm}$ radius rounded steel knife edges. Testing was carried out in distilled water at $37{ }^{\circ} \mathrm{C}$ with the load applied at the midpoint of the samples. The flexural strength was calculated for the monolayer specimens according to Equation 1.

$$
\sigma_{f}=\frac{3 F L}{2 w h^{2}}
$$

Where $\sigma$ is the maximum center tensile stress (MPa), $\mathrm{F}$ is the load at fracture $(\mathrm{N}), \mathrm{L}$ is the distance of the two supports $(\mathrm{mm}), \mathrm{w}$ is the width of the specimen $(\mathrm{mm})$, and $\mathrm{h}$ is the height of the specimen ( $\mathrm{mm}$ ).

For bilayer specimens, flexural strength was calculated using Equation 2, where $\sigma_{\mathrm{f}}$ is the maximum center tensile stress $(\mathrm{MPa}), \mathrm{L}$ is the distance of the two supports $(\mathrm{mm}), \mathrm{P}$ is the load at fracture $(\mathrm{N}), \mathrm{E}_{\mathrm{t}}$ is the Young modulus (according to the manufacturer) of material under tensile stress $(\mathrm{GPa}), t_{t}$ is the height of the material under tensile stress $(\mathrm{mm}), \mathrm{E}_{\mathrm{c}}$ is the Young modulus (according to the manufacturer) of material under compression $(\mathrm{GPa}), \mathrm{t}_{\mathrm{c}}$ is the height of the material under tensile stress $(\mathrm{mm})$, and $\mathrm{w}$ is the width of the specimen $(\mathrm{mm})$.

$$
\sigma f=\frac{3 E_{t} L P\left(E_{c} t_{c}^{2}+2 E_{c} t_{c} t_{t}+E_{t} t_{t}^{2}\right)}{2 w\left(E_{c .}^{2} t_{c .}^{4}+4 E_{c .} E_{t} t_{c .}^{3} t_{t}+6 E_{c} E_{t} t_{c .}^{2} t_{t .}^{2}+4 E_{c .} E_{t} t_{c} t_{t}^{3}+E_{t .}^{2} t_{t}^{4}\right)}
$$

The flexural strength data for each design group were analyzed using one-way ANOVA $(\alpha=0.05)$, and Tukey posthoc test $(\alpha=0.05)$ was used to identify differences among the cooling methods.

\section{Results}

The mean values (MPa), standard deviations, and coefficients of variance for three-point flexural strength are presented in Table 2. The results of one-way ANOVA for bilayer specimens $3 \mathrm{Y}$-TZP/VM9 with porcelain on lower surface (PB) were statistically significant (Table 3). Tukey post-hoc test showed the highest flexural strength for fast cooling and the lowest for slow cooling; the normal cooling was not different from fast and slow cooling. The results of the one-way ANOVA for PM (Table 4), ZM (Table 5), and ZB (Table 6) were not statistically significant $(\alpha>0.05)$.
Table 2. Mean (MPa) of flexural strength, standard deviation, and coefficient of variance.

\begin{tabular}{lllll}
\hline Group & Cooling & Average & Sd & Covar \\
PM & Slow & 74.4 & 9.0 & $12.1 \%$ \\
& Normal & 75.4 & 7.7 & $10.2 \%$ \\
& Fast & 77.9 & 11.1 & $14.2 \%$ \\
ZM & Slow & 835.5 & 129.9 & $15.5 \%$ \\
& Normal & 873.0 & 140.1 & $16.1 \%$ \\
& Fast & 817.1 & 95.2 & $11.6 \%$ \\
PB & Slow & 49.3 & 10.1 & $20.5 \%$ \\
& Normal & 56.1 & 11.0 & $19.6 \%$ \\
& Fast & 67.5 & 16.7 & $24.8 \%$ \\
& Slow & 572.5 & 136.5 & $23.8 \%$ \\
& Normal & 590.6 & 117.4 & $19.9 \%$ \\
& Fast & 691.3 & 177.8 & $25.7 \%$ \\
\hline
\end{tabular}

\section{Discussion}

The null hypothesis was partially rejected. In monolayer specimens, the cooling method did not change the flexural strength. The lack of effect of the cooling rate for zirconia monolayer specimens was possibly because the temperature of simulating the feldspathic porcelain sintering was below the temperature required to induce phase transformation in the used Y-TZP. However, for porcelain monolayer specimens, could be expected thermal material tempering on fast cooling method due to very high heat transfer between the material and the environment ${ }^{7,19-20}$ or microstructural changes on vitreous matrix on slow cooling ${ }^{21-22}$. Moreover, the PM group, as monolayer specimens, did not have any effect of thermal expansion coefficient mismatch on the framework material and consequent residual tension.

For bilayer specimens, in ZB groups, the cooling method was not able to affect the flexural strength because zirconia was on the lower surface and it was more directly under tension and might be responsible for the whole sample strength ${ }^{23-24}$.

In PB groups, the cooling method affected the flexural strength. This could be attributed to residual tension. At temperatures above the glass transition temperature ( $\mathrm{Tg}-$ around $600{ }^{\circ} \mathrm{C}$ ) stresses are relieved by plastic deformation since the porcelain behaves as a viscoelastic liquid and allows the rearrangement of the atoms within the structure. When the temperature declines to the glass transition region, atomic displacement is more difficult to occur. Thus, the viscous liquid porcelain gets denser with the atoms in closer packing. At temperatures below the Tg, porcelain is solid and structural rearrangements are impossible. At this moment, residual stress develops from the potential discrepancy in volume, density and viscosity between layers of porcelain that are below (external) and above (internal) the glass transition phase. This process could be affected by the cooling rate, thickness, thermal conductivity, and the mismatch in coefficient of thermal expansion of both the porcelain and zirconia core cor11. $^{7}$.

In the fast cooling rate, the external regions cool faster 
Table 3. One-way ANOVA results of flexural strength values of porcelain monolayer design

\begin{tabular}{lclccc}
\hline & Sum of squares & df & Mean Square & F-Ratio & Significance \\
Inter-group & 97.58 & 2 & 48.792 & 0.5574 & 0.582 \\
Intra-group & 3680.00 & 42 & 87.527 & & \\
Total & 3777.58 & 44 & & & \\
\hline
\end{tabular}

Table 4. One-way ANOVA results of flexural strength values of zirconia monolayer design

\begin{tabular}{lclccc}
\hline & Sum of squares & df & Mean Square & F-Ratio & Significance \\
Inter-group & $24,400.0$ & 2 & $12,200.0$ & 0.8025 & 0.541 \\
Intra-group & $638,000.0$ & 42 & $15,200.0$ & & \\
Total & $662,400.0$ & 44 & & & \\
\hline
\end{tabular}

Table 5. One-way ANOVA results of flexural strength values of zirconia bilayer design

\begin{tabular}{lclllc}
\hline & Sum of squares & $\mathrm{df}$ & Mean Square & F-Ratio & Significance \\
Inter-group & $123,000.0$ & 2 & $61,500.0$ & 2.8802 & 0.066 \\
Intra-group & $897,000.0$ & 42 & $21,300.0$ & & \\
Total & $1020,000.0$ & 44 & & & \\
\hline
\end{tabular}

Table 6. One-way ANOVA results of flexural strength values of porcelain bilayer design

\begin{tabular}{lcllcc}
\hline & Sum of squares & df & Mean Square & F-Ratio & Significance \\
Inter-group & $2,530.0$ & 2 & $1,270.0$ & 7.5813 & 0.002 \\
Intra-group & $7,010.0$ & 42 & 167.0 & & \\
Total & $9,540.0$ & 44 & & & \\
\hline
\end{tabular}

and the temperature gradients through the porcelain increase, concentrating stresses near the surface. Thus, stress development increases with higher porcelain thickness, faster cooling rate, and lower thermal conductivity ${ }^{10}$. Moreover, the mismatch between thermal expansion coefficient and thermal gradients inevitably makes the layered structures subject to a high residual stress when cooled from a furnace temperature ${ }^{11}$. The highest flexural strength observed in fast cooling in the PB group might be associated to compressive forces on the surface. However, when those structures are subjected to cyclic loads such as chewing, chipping or delamination may occur. Thus, the dental laboratory technician must be careful with the fast cooling method.

The slow cooling method has been proposed to decrease the mismatch of coefficients of thermal expansion and thermal diffusion. It was expected that this method would allow cooling of both materials at a more uniform rate. However, annealing of the porcelain occurs when the restoration is cooling slowly. This reduces substantially the possibility of surface compressive force formation, which is believed to strengthen the restoration. However, this speculation was not confirmed in this study. In fact, the slow cooling method could be harmful since it adds more heat to the restoration and, thus, increases the potential for induction of thermal strains and possible zirconia phase transformation ${ }^{25}$. Nevertheless, the interaction of zirconia and porcelain during veneering requires more investigation, at several principles of thermodynamics.

It is important to observe that flexural strength with bar samples is a simplified method for predicting clinical performance of these materials. However, fixed partial dentures may show a different behavior than bars due to their complex geometry. Additionally, in the oral environment these materials are susceptible to different chemical and physical fatigues that were not reproduced in this study.

Then, different cooling methods affected only the flexural strength of bilayer specimens with porcelain in lower surface. The complex residual thermal stresses generated in bilayer specimens could be associated with thermal tempering stress, which probably did not occur in the slow cooling method.

\section{Acknowledgements}

This research was supported by research grant FAPESP (2009/17735-8 and 2010/05469-9).

\section{References}

1. Guazzato M, Albakry M, Ringer SP, Swain MV. Strength, fracture toughness and microstructure of a selection of all-ceramic materials. Part II. Zirconia-based dental ceramics. Dent Mater. 2004; 20: 449-56.

2. Vichi A, Louca C, Corciolani G, Ferrari M. Color related to ceramic and zirconia restorations: a review. Dent Mater. 2011; 27: 97-108. 
3. Sailer I, Feher A, Filser F, Gauckler LJ, Lüthy H, Hämmerle $\mathrm{CH}$. Fiveyear clinical results of zirconia frameworks for posterior fixed partial dentures. Int J Prosthodont. 2007; 20: 383-8.

4. Sailer I, Pjetursson BE, Zwahlen M, Hammerle $\mathrm{CH}$. A systematic review of the survival and complication rates of all-ceramic and metal-ceramic reconstructions after an observation period of at least 3 years. Part II: Fixed dental prostheses. Clin Oral Implants Res. 2007; 18(Suppl 3): 86-96.

5. Pjetursson BE, Sailer I, Zwahlen M, Hammerle CH. A systematic review of the survival and complication rates of all-ceramic and metal-ceramic reconstructions after an observation period of at least 3 years. Part I: Single crowns. Clin Oral Implants Res. 2007; 18(Suppl 3): 73-85.

6. Raigrodski AJ, Hillstead MB, Meng GK, Chung KH. Survival and complications of zirconia-based fixed dental prostheses: a systematic review. J Prosthet Dent. 2012; 107: 170-7.

7. Swain MV. Unstable cracking (chipping) of veneering porcelain on allceramic dental crowns and fixed partial dentures. Acta Biomater. 2009; 5: 1668-77.

8. Benetti P, Pelogia F, Valandro LF, Bottino MA, Bona AD. The effect of porcelain thickness and surface liner application on the fracture behavior of a ceramic system. Dent Mater. 2011; 27: 948-53.

9. Guess PC, Kulis A, Witkowski S, Wolkewitz M, Zhang Y, Strub JR. Shear bond strengths between different zirconia cores and veneering ceramics and their susceptibility to thermocycling. Dent Mater. 2008; 24 : 1556-67.

10. Guazzato M, Walton TR, Franklin W, Davis G, Bohl C, Klineberg I. Influence of thickness and cooling rate on development of spontaneous cracks in porcelain/zirconia structures. Aust Dent J. 2010; 55: 306-10.

11. Zhang Z, Zhou S, Li Q, Li W, Swain MV. Sensitivity analysis of bi-layered ceramic dental restorations. Dent Mater. 2012; 28: e6-14.

12. Sundh A, Molin M, Sjogren G. Fracture resistance of yttrium oxide partiallystabilized zirconia all-ceramic bridges after veneering and mechanical fatigue testing. Dent Mater. 2005; 21: 476-82.

13. Rosentritt M, Steiger D, Behr M, Handel G, Kolbeck C. Influence of substructure design and spacer settings on the in vitro performance of molar zirconia crowns. J Dent. 2009; 37: 978-83.

14. Komine F, Saito A, Kobayashi K, Koizuka M, Koizumi H, Matsumura H. Effect of cooling rate on shear bond strength of veneering porcelain to a zirconia ceramic material. J Oral Sci. 2010; 52: 647-52.

15. Heintze SD, Rousson V. Survival of zirconia- and metal-supported fixed dental prostheses: a systematic review. Int J Prosthodont. 2010; 23: 493-502.

16. Fischer J, Stawarczyk B, Hammerle $\mathrm{CH}$. Flexural strength of veneering ceramics for zirconia. J Dent. 2008; 36: 316-21.

17. Zhang Z, Li Q, Li W, Swain M. Transient modelling of thermal processing for ceramic prostheses. J Austr Ceram Society. 2009; 45: 40-8.

18. Gostemeyer G, Jendras M, Dittmer MP, Bach FW, Stiesch M, Kohorst P. Influence of cooling rate on zirconia/veneer interfacial adhesion. Acta Biomater. 2010; 6: 4532-8.

19. DeHoff $\mathrm{PH}$, Anusavice KJ, Vontivillu SB. Analysis of tempering stresses in metal-ceramic disks. J Dent Res. 1996; 75: 743-51.

20. MainjotAK, Schajer GS, Vanheusden AJ, Sadoun MJ. Influence of zirconia framework thickness on residual stress profile in veneering ceramic: Measurement by hole-drilling. Dent Mater. 2012; 28: 378-84.

21. Mackert JR Jr, Evans AL. Effect of cooling rate on leucite volume fraction in dental porcelains. J Dent Res. 1991; 70: 137-9.

22. Mackert JR Jr, Rueggeberg FA, Lockwood PE, Evans AL, Thompson WO. Isothermal anneal effect on microcrack density around leucite particles in dental porcelain. J Dent Res. 1994; 73: 1221-7.

23. White SN, Miklus VG, McLaren EA, Lang LA, Caputo AA. Flexural strength of a layered zirconia and porcelain dental all-ceramic system. J Prosthet Dent. 2005; 94: 125-31.

24. Fleming GJ, El-Lakwah SF, Harris JJ, Marquis PM. The effect of core: dentin thickness ratio on the bi-axial flexure strength and fracture mode and origin of bilayered dental ceramic composites. Dent Mater. 2005; 21: 164-71.
25. Keough BE, Kay HB, Sager RD, Keen E. Clinical performance of scientifically designed, hot isostatic-pressed (HIP'd) zirconia cores in a bilayered allceramic system. Compend Contin Educ Dent. 2011; 32: 58-68. 